\title{
Erratum to: Enhanced Magnetoelectric Coupling in Layered Structure of Piezoelectric Bimorph and Metallic Alloy
}

\author{
V.M. PETROV,${ }^{1,2}$ M.I. BICHURIN,${ }^{1}$ K.V. LAVRENTYEVA, ${ }^{1}$ \\ and V.S. LEONTIEV ${ }^{1}$ \\ 1.--Institute of Electronic and Information Systems, Novgorod State University, 41 \\ B.S.-Peterburgskaya Street, 173003 Veliky Novgorod, Russia. 2.—e-mail: vladimir.petrov@novsu.ru
}

Erratum to: Journal of ELECTRONIC

MATERIALS

DOI 10.1007/s11664-016-4628-9

The spelling of V.S. Leontiev's family name was incorrect in the original publication. The article has been updated to correct this error. 